\title{
Managing Assessment: Using Technology to Facilitate Change
}

\author{
G. Welsh
}

Massey University, College of Education, Centre for Educational Development, Palmerston North, New Zealand

Key words: Computerised School Information Systems, Professional Development, Assessment, Effective School Development

Abstract: This paper describes a number of developments focusing on school-wide assessment, recording and reporting. Such factors as secondary school culture and change, the external pressures to comply, and action research elements are considered. Discussion of findings from these projects reveal: (1) the influential role that computer software can play in collaborative developments, and (2) the relationship between software system implementation and cultural change. This suggests ways that CSIS could be more productively used to assist with school development.

\section{INTRODUCTION}

The evolution of computerised school information systems (CSIS) in New Zealand secondary schools has been characterised by an emphasis on the automation, and quest to improve efficiency, of administrative processes. The emerging challenge is to utilise the power of the microprocessor to promote and facilitate school developments that impact positively on student achievement. This may necessitate a re-examination of the established, and often disparate, functions of professional development services and CSIS providers. 


\section{BACKGROUND}

New Zealand schools have experienced unprecedented change during the last decade. Radical restructuring of the frameworks for both curriculum and qualifications followed a movement towards self-management in 1989. The curriculum framework, consisting of seven essential learning areas, has been progressively introduced with completion not expected until 2002. The new Qualifications Framework, based on unit standards, was launched in 1994.

The introduction of unit standards signalled an emphatic movement towards the use of internal assessment for awarding qualifications at the senior secondary school level. Each course had unit standards defined, which described the outcomes and the performance criteria that would be used to determine whether or not the standard had been achieved. Approximately five to eight standards would be used for each full year course and each standard had a number of credits associated with it. The plan, which has since been modified, was for these credits to contribute to a National Certificate of Educational Achievement, at years 12 and 13, and other, subject specific, National Certificates.

Secondary schools were faced with the task of recording and reporting unit standard results to the New Zealand Qualifications Authority ${ }^{1}$. This, by itself, was not a major issue as the significant suppliers of CSIS had modules available which satisfied this need. At this time a model was being presented to school audiences demonstrating how the recording, reporting and evaluation of assessment data, relating to the curriculum framework, could be relatively straight forward IF there was a common assessment 'currency' across the school. This model was converted into software form for demonstration purposes. However, the staggered introduction of curriculum statements for each of the essential learning areas, and their Maori equivalents, meant that schools were not ready to tackle whole-school implementation issues. Several school managers believed that this software model could be applied in an area where there was already an established school-wide assessment currency: unit standards.

Thirty-five secondary schools are currently involved with the unit standard component of this development. Thirteen secondary schools, most of whom also belong to the first group, are part of a more extensive project with the goal of improving student achievement by developing an approach to assessment in secondary schools based on standards and emphasising the essential role that formative assessment can play. In many, but not all, of the schools belonging to the second group, unit standards have served as a lever

${ }^{1}$ The New Zealand Qualifications Authority is a Crown Entity established to co-ordinate national qualifications. 
to introduce a similar approach to assessment in the junior school. This paper is a commentary on developments involving schools from the second group.

Participation in these professional and school development projects is voluntary - schools may join or leave at any time. The schools vary in size from a little over 100 students to over 1000 with a mode of approximately 700 students. The junior division of these schools generally refers to years 9 and 10, or students in the 13-15 age group. All participating schools utilise the MUSAC ${ }^{2}$ school information system and, in particular, the MUSAC Pupil Files program which is used to manage student personal data.

Although essentially self-managing, schools must comply with several sets of guidelines promulgated by the Ministry ofEducation (MOE). One of these guidelines, National Administration Guideline 1, or NAGl as it is commonly called, refers to the collection and utilisation of assessment data based on the curriculum objectives contained in the national curriculum statements for each essential learning area. The Education Review Office ${ }^{3}$ uses the guidelines to audit school compliance and, to a limited extent, school performance. Many, if not most, secondary schools have had difficulty in satisfying NAGl and, consequently, ERO. Typical expressions included in the ERO generated audit reports ${ }^{4}$ for secondary schools include:

- Implementation of an agreed school-wide system should enable the school to improve evaluation of student progress;

- The school is knowledgeable about the significance of assessment but has still to decide what is best practice for school-wide adoption; and

- The school needs to face the challenge of reviewing its approaches to assessment, recording and reporting, and develop systems that enable it to demonstrate student progress more effectively.

Secondary schools operate in a competitive environment with increasing student mobility contributing to significant fluctuation in school rolls. The public nature of the ERO reports therefore provides a strong motivation for action to address non-compliance issues, in particular. Most of the schools participating in these professional and school development projects derived their initial impetus in this way.

\footnotetext{
${ }^{2}$ Massey University School Administration by Computer (MUSAC) software is used extensively in a large number of New Zealand schools and is continually evolving to meet the needs ofa rapidly changing educational environment. Refer to the MUSAC website at http://musac.massey.ac.nz

3 The Education Review Office (ERO) is the government department which reports publicly on the quality of education in all New Zealand schools and early childhood centres, including private schools, kura kaupapa Maori (Maori language immersion schools), special schools and kohanga reo (Maori language early childhood groups).

${ }^{4}$ These reports are available from http://www.ero.govt.nz
} 
The method used for these school developments varied according to the size of the schools and their state of readiness. However, the use of several in-school workshops for the whole staff (small school) or curriculum representatives (larger school) has been common. These workshops have covered:

- Issues surrounding the implementation of the curriculum framework;

- The need for transparency from assessment to reporting;

- Formative assessment and reporting;

- Agreement on the desirability of a common assessment currency and what this should be;

- Possibilities for the aggregation and analysis of achievement data - will it lead to better programmes and learning?;

- The benefits ofschool-wide consistency; and

- A means of achieving this.

The use of CSIS to promote consistent approaches to assessment was to be an essential feature (see James, 1998).

\section{USING CSIS TO FACILITATE CHANGE}

Progressing with these projects meant overcoming significant barriers. Autonomous subject departments in secondary schools, the staggered introduction of curriculum statements, and the legacy of decades of reliance on external examinations have been the most prominent obstacles. The software developed to support these projects has played an integral part, not only in helping teachers conceptualise the underpinning model, but in actually implementing their developmental plans. It is a collaborative development with all participating schools and is continually evolving as our experiences with and knowledge of assessment, reporting and evaluation expands. 
Table 1. The evolving software

\begin{tabular}{|c|c|}
\hline 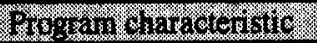 & 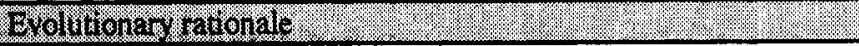 \\
\hline Networkability & $\begin{array}{l}\text { As the reporting aspect gained momentum, simultaneous access } \\
\text { by a number of staff was enabled. }\end{array}$ \\
\hline Portability of data & $\begin{array}{l}\text { Constraints on teachers' in-school time created a need to export or } \\
\text { import subsets of data to be used on a remote workstation. As } \\
\text { well as maintaining the integrity of the database, issues such as } \\
\text { low machine memory and speed of the remote workstations } \\
\text { needed to be addressed. }\end{array}$ \\
\hline Ease of use & $\begin{array}{l}\text { Teachers bring with them a range of experiences and skills, and } \\
\text { unnecessary complexity or procedures discourages rather than } \\
\text { facilitates the utilisation ofCSIS. }\end{array}$ \\
\hline Security and backup & $\begin{array}{l}\text { Experience demanded that multiple backup scenarios were built } \\
\text { in, e.g. automatically saving data when a window was closed. } \\
\text { Password protection was needed to maintain global configuration } \\
\text { integrity. }\end{array}$ \\
\hline Limited flexibility & $\begin{array}{l}\text { It transpired that there needed to be a balance between flexibility } \\
\text { (to allow for departmental or school peculiarities) and the use of } \\
\text { 'constants' (to emphasis the desired assessment model and ensure } \\
\text { school-wide consistency). }\end{array}$ \\
\hline Reporting & $\begin{array}{l}\text { The ability to generate reports directly from assessment data was } \\
\text { an important principle, which was incorporated. }\end{array}$ \\
\hline Data entry & $\begin{array}{l}\text { Apart from report comments (which can be automated) this is } \\
\text { achieved, though not exclusively, through mouse manipulation. A } \\
\text { compromise needed to be made between data complexity and ease } \\
\text { of use. }\end{array}$ \\
\hline Compatibility & $\begin{array}{l}\text { Data transfer from MUSAC or other systems is seamless and } \\
\text { automatic. }\end{array}$ \\
\hline $\begin{array}{l}\text { Evaluation/analysis of } \\
\text { data }\end{array}$ & $\begin{array}{l}\text { This is at a formative stage as schools come to terms with a } \\
\text { school-wide assessment 'currency' and the use of the available } \\
\text { technology tools.' }\end{array}$ \\
\hline Year to year continuity & $\begin{array}{l}\text { The facility to archive reports and assessment information } \\
\text { generally was anticipated. This does present some issues, } \\
\text { however }\end{array}$ \\
\hline
\end{tabular}

The temptation to develop a flexible open-ended program needed to be tempered with the current state of computer literacy among secondary school teachers. As Ayres, Nolan and Visscher (1998) point out, senior managers and administration staff are the major users of CSIS, predominantly for administrative purposes. There appears to be a direct relationship between the flexibility of and the complexity of the software used in this context. A conscious decision was therefore made to restrict the flexibility in an attempt

${ }^{5}$ Described by Nolan, Fulmer and Taylor (1998) as moving from data management to information management.

${ }^{6}$ Frank and Fulmer (1998) explain that multi-level data is very powerful but can also be very condemning. 
to maximise ease of use. There exists no obvious impediment, from a data structure perspective, to the adoption of a more sophisticated open-ended system once the development objectives have been achieved.

There is no escaping the need to report to caregivers or parents and most schools demand consistency in the manner in which this is done. The generation of computerised reports, unavoidable in the context of these projects, provided a useful focus for the up-skilling of teachers in the use of CSIS. This up-skilling was managed through peer facilitation with little external input. One difficulty faced was the tendency to unduly focus on the format and layout of a report rather than the content. This has not been overcome in all schools but the use of trials, targeting specific curriculum areas or year levels, and the subsequent process of diffusion shows promise.

The software has played an invaluable role in motivating participants but, like other school development projects, essential components of change management also need to feature - strong internal leadership, a culture accepting of change, and a value placed on Professional Development. Predominant variables and the pace of change vary significantly from school to school. Identification of the factors contributing to this has not revealed anything beyond what contemporary research in this domain tells us, but contextualising is helping schools to understand their own complex culture and plan for successful change.

Table 2. Summary of progress to-date and cultural characteristics

\begin{tabular}{|l|l|}
\hline Stuck on first base & Predominantly acedemically focused (the school and/or the \\
& managers and/or the community), with an emphasis on external \\
& examinations. \\
& Hierarchical management structure not predisposed to grass \\
& roots development. \\
& An emphasis on compliance rather than on development (often \\
& for reasons of work load). \\
& Project capture by teacher(s) with specific curriculum bias. \\
\hline Deliberating on & $\begin{array}{l}\text { Some strongly independent, autonomous subject departments. } \\
\text { third base }\end{array}$ \\
& $\begin{array}{l}\text { Smaller school where work-load is not easily shared. } \\
\text { Caking a breather - change can be energy sapping. }\end{array}$ \\
& Cautionary movement anticipating further, alternative rather than \\
progressive change.
\end{tabular}




\section{SUMMARY}

Most of the software currently utilised in secondary schools has been designed along traditional lines and has not changed significantly ${ }^{7}$, user interface/operating system and functionality excepted, over the last decade (see Nolan, Fulmer and Taylor, 1998). The small New Zealand market possibly inhibits extensive research and development in this area. Consequently, schools have had to fit the system which is contrary to what Nolan \& Lambert (2001) report as being necessary for the proper utilisation of CSIS. The software used in these school projects has been developed collaboratively and in parallel with the professional development programme. The progress made can be attributable, in no small way, to the use ofCSIS tools to model ideas, overcome workload issues and handle the complexity involved in collating student learning outcomes from diverse curriculum areas. Bringing separate subject departments, often with their own divergent approaches, together has been an essential phase of this development relying heavily on the purpose built software.

The computer programs that have evolved out of these school developments have been designed to complement rather than compete with commercially produced software. The focus has been on whole-school development. When attempting to devise solutions with open-ended CSIS, schools have effectively been left to their own devices. External software support is confined to 'training in the use of' and schools receive no support, from this source, with the underpinning philosophies, rationale and implications. In fact, a number of schools in this region have re-invented antiquated systems for reporting under the guise of 'progressive' computerisation. Schools ostensibly faced with the same challenges (in relation to NAG1) have reacted in many different ways with quite diverse outcomes. These outcomes, or developments, rely very much on the style of internal leadership and the nature of the 'resident' technological expertise.

These projects are dynamic in the sense that each milestone achieved induces investigative urges and the formulation of fresh objectives. One school, through the principle co-ordinator, has recently completed an action research study on the impact that this project has had on teacher planning, assessment methodology and, not surprisingly, student achievement.

${ }^{7}$ MUSAC's Classroom Manager promises to contradict this. 


\section{IMPLICATIONS}

Professional Development and software support for schools have been treated as different entities, provided by different organisations and funded from different sources. For significant developments involving technology tools, such as those described here, this is not necessary or even desirable. An analogous comparison could be made with the beneficial process of linking learning and assessment more closely. The emerging concept is therefore the utility of merging the functions of external professional development and CSIS support as a means of enabling effective school development.

There is potential to generate 'indigenous' research through collaborative projects 'owned' by the school. If the ultimate goal is to raise student achievement then schools need to develop the capacity to find out whether this has happened. The willingness, and capacity, to conduct indigenous research should be strongly encouraged as it indubitably enhances the school development process.

\section{REFERENCES}

Ayers, D., Nolan, C.J.P., \& Visscher, A.J. (1998). Computerised school information systems: Researching New Zealand usage patterns and levels of use. In C. Fulmer, B. Barta, \& P. Nolan (Eds.), The integration of information for educational management. Whitefield, ME: Felicity Press.

Frank, F.P., \& Fulmer, C.L. (1998). The dysfunctional side of educational organisations: Themes from clinical information system development. In C. Fulmer, B. Barta, \& P. Nolan (Eds.), The integration ofinformationfor educational management. Whitefield, ME: Felicity Press.

James, M. (1998). Using assessment for school improvement. Oxford: Heinemann Educational Press.

Nolan, C.J.P., \& Lambert, M. (2001). Information systems for leading and managing schools: Changing the paradigm. In P. Nolan \& A. Fung (Eds.), Institutional improvement through information technology in educational management. London: Kluwer.

Nolan, C.J.P., Fulmer, C.L., \& Taylor, R. (1998). Four computerised school information systems: Summary discussion. In C. Fulmer, B. Barta, \& P. Nolan (Eds.), The integration of information for educational management. Whitefield, ME Felicity Press.

Education Review Office (2000). School audit reports. Wellington: ERO. [http://www.ero.govt.nz]

Ministry of Education (1999). The national administration guidelines (revised). Wellington: Ministry of Education. 